\title{
Mechanism of after-ripening of the cultivated champignon (Agaricus bisporus) during storage
}

\author{
E. KOVÁCS and E. ZUKÁL
}

\begin{abstract}
KOVĀCS, E. \& ZUKĀL, E. 1978: Mechanism of after-ripening of cultivated champignon (Agaricus bisporus) during storage. - Karstenia 18 (suppl.).

Growth of the length of the fruiting body, as well as increase in the pileus diameter are much slower processes than that of the pileus opening. The opening being developed on the pileus was expressed in the percentage of the original pileus diameter and value obtained by this way was called of slit-width.

Optimum temperatures required for the experiments were fixed. In case of a 40-60-hour observation time a temperature of $16-20^{\circ} \mathrm{C}$ is fovourable, while carrying out the experiments at $25^{\circ} \mathrm{C}$ is only expedient if the observation does not exceed 30 hours. In these phases the pileus opening is linear in the function of time. We filmed the pileus opening and by evaluating the data of the film made, it was found out that opening of the pileus and by evaluating the data of the film made, it was found out that opening of the pileus quick phase is presumably a mechanical motion with the aim of spore discharge.

Some authors observed the periodicity of spore discharge and that process significantly depends on the fluctuation of relative humidity (RH), increase in RH is followed by discharging of the spores.

In our experiments regarding the plleus opening the latter has formed a multi-stage process with the fluctuation of relative humidity.

E. Kovâcs, Central Food Research Institute, Herman Ottó u. 15, H-1022 Budapest, Hungary. E. Zukāe, University of Agricultural Sciences, Mosonmagyarōvāir, Hungary.
\end{abstract}

\section{Introduction}

The storage life of Agaricus bisporus is extremely limited and even under refrigeration is not more than 1-3 days. Deterioration of the quality is apparent in loss of weight, browning, and opening of the cap. Storage efficiency is largely dependent on the state of maturity of the goods stored. In the case of champignons, maturity is established by the extent of opening of the cap because on the fully developed mushroom this is the most striking change. In eariier experiments it was established that the sensory properties change in direct relation to the extent of cap opening. The aim of these experiments was to study the mechanism of ripening during storage of the harvested mushrooms.

\section{Materials and methods}

The Agaricus bisporus used in the experiments was obtained from the DUNA Agricultural Co-operative, Budapest.

Fig. I shows the measurements carried out on the mushrooms: 1) cap diameter in $\mathrm{mm}$; 2) distance between the stipe and the edge of the cap, or in other words the opening in $\mathrm{mm}$. The opening was expressed as percentage of the cap diameter as established upon harvesting, and this was called the relative opening (relative \%). Measurements were carried out with a sliding caliper.

Mushrooms of 3-5 cm cap diameter, 150-200

pieces per experiment, were used. Each experiment was repeated three times. Samples were stored at 16, 20 and $25^{\circ} \mathrm{C}$ and at $97-99 \%$ relative humidity. Results were compared by $x^{2}$ test on the basis of the frequency distribution of opening.

\section{Results and conclusions}

The frequency distribution of the relative openings of samples incubated at 16, 20 and $25^{\circ} \mathrm{C}$ for 20-24 and 44-45 $\mathrm{h}$ are presented in Fig. 2 .

As expected, the cap openings differed to a

highly significant degree at different storage temperatures. This was confirmed by the $x^{2}$ test.

On the basis of preliminary experiments 5 char-

Fig. 1. Measurements carried out on the mushrooms.

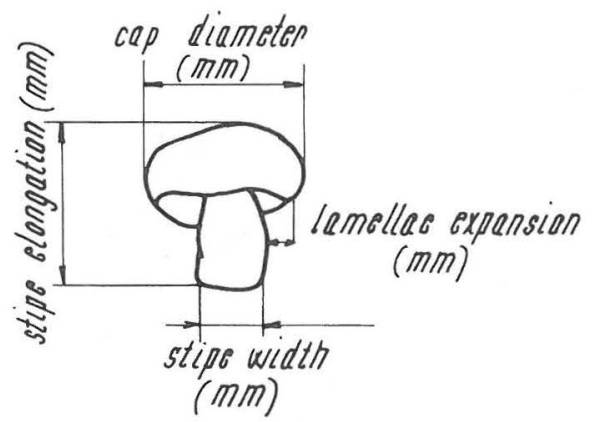


acteristic opening ranges were selected: A. mushrooms with closed cap (1-10\%); B. mushrooms with $11-21 \%$ rel. opening; C. mushrooms with $22-28 \%$ rel. opening; D. mushrooms with $29-38 \%$ rel. opening; E. mushrooms with 39-46\% rel. opening.

Mushrooms with 1-10\% opening occurred rarely, because the veil begins to separate from the stipe while the cap is still closed. However, in these experiments only those caps were considered opened on which the veil separated from the stipe to at least $50 \%$.

Fig. 2. Frequency distribution of relative openings of samples incubated at $16^{\circ}, 20^{\circ}$ and $25^{\circ} \mathrm{C}$ for 20-24 h and $44-45 \mathrm{~h}$. ( $x \times x=$ highly significant difference).
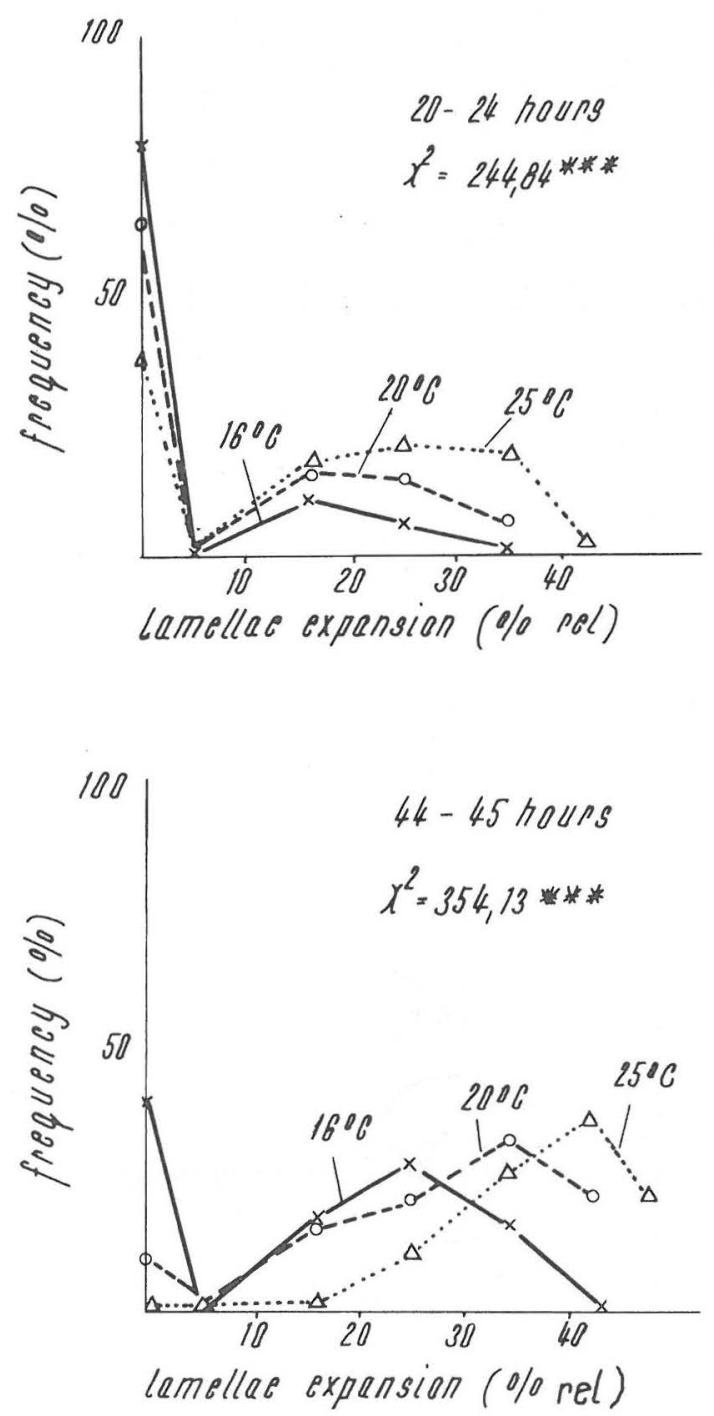

In Fig. 3 the frequency distribution of each group as a function of the observation period is illustrated. Diagram A shows the percentage of mushrooms with closed caps after incubation at 16,20 and $25^{\circ} \mathrm{C}$ as a function of time. During storage at 16 and $20^{\circ} \mathrm{C}$ the number of mushrooms with closed cap shows a linear reduction $\left(16^{\circ} \mathrm{C}: \mathrm{r}=0.9983, \mathrm{y}=127.03+(-2.23) \mathrm{x}\right.$; $\left.20^{\circ} \mathrm{C}: \mathrm{r}=0.9150, y=93.99+(-1.56) x\right)$. At $25^{\circ} \mathrm{C}$ the change is much more rapid and is linear only in the first $30 \mathrm{~h}$ of observation $\left(25^{\circ} \mathrm{C}: \mathrm{r}=0.9194, \mathrm{y}=\right.$ $54.52+(-1.17) x)$. Thus it seems expedient to carry out the experiments at $20^{\circ} \mathrm{C}$. Twenty-five degrees may be applied only if the observation period is not longer than 25-30 h.

In diagram $B$ the mushrooms with $11-21 \%$ relative opening are presented as a function of the observation period. This group contained mushrooms with $4-8 \mathrm{~mm}$ opening. The frequency distribution in this group seems to be constant and independent of time.

In graph $C$ the frequency distribution of mushrooms with $22-28 \%$ rel. opening (corresponding to 9-12 $\mathrm{mm}$ opening) is presented at incubation temperatures 16 and $20^{\circ} \mathrm{C}$. As may be seen in the graph, the frequency first increases with time, later becoming constant. This last phase varies with different temperatures. At $16^{\circ} \mathrm{C}$ it is nearly constant, while at $25^{\circ} \mathrm{C}$ it diminishes rapidly.

As can be seen in graph $D$ the frequency of mushrooms belonging to the group of $29-38 \%$ relative opening increases with time when incubated at $16^{\circ}$ or $20^{\circ} \mathrm{C}$. At $25^{\circ} \mathrm{C}$ the process is similar but much more rapid. After $30 \mathrm{~h}$ the number of mushrooms rapidly decreases, that is, further caps open.

The relative opening of $39-47 \%$, presented in graph E, means practicaliy the complete opening of caps. The effect of temperature is evident in this figure, with accumulation of mushrooms in this opening range. From the above results it may be concluded that the various opening values are not achieved by a continuous but by a periodical process.

It appears that up to $12 \mathrm{~mm}$ opening (corresponding to $11-28 \%$ relative opening) the process is continuous. In these ranges mushrooms do not accumulate and thus they are independent of time.

In the 12-16 mm range (corresponding to $29-38 \%$ relative opening) a sudden opening was observed. This is shown in Fig. 4, where the periodicity of opening is well visible. Data were obtained by the evaluation of a process shot. The mushrooms were kept in a dark room at $20^{\circ} \mathrm{C}$ and $80 \%$ relative humidity. Shots were taken with an automatic camera by $20 \mathrm{sec}$ exposures at 5 min intervals.

The rapid phase of opening is represented by a leap, probably by mechanical means in consequence of the change in turgor of the cells.

Haar \& Kramer in 1970 and Rockett \& Kramer in 1974 have published their observations on the periodical shedding of spores of basidial fungi at a temperature of $20^{\circ} \mathrm{C}$ and relative humidities of 40-100, 60100 and $80-100 \%$. They established, among others, that 
Fig. 3. Frequency distribution of the different groups ( $A, B, C, D$ and $E$ ) as a function of the observation period.

$A, B, C, D$ and $E$ are the characteristic opening ranges (\%).
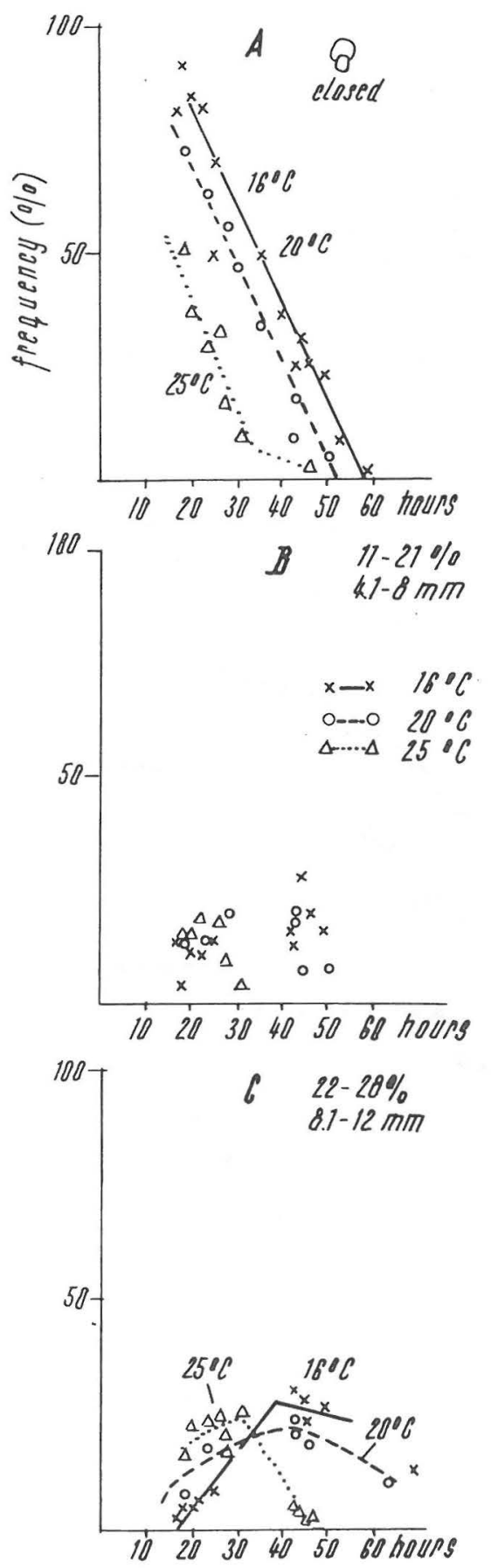
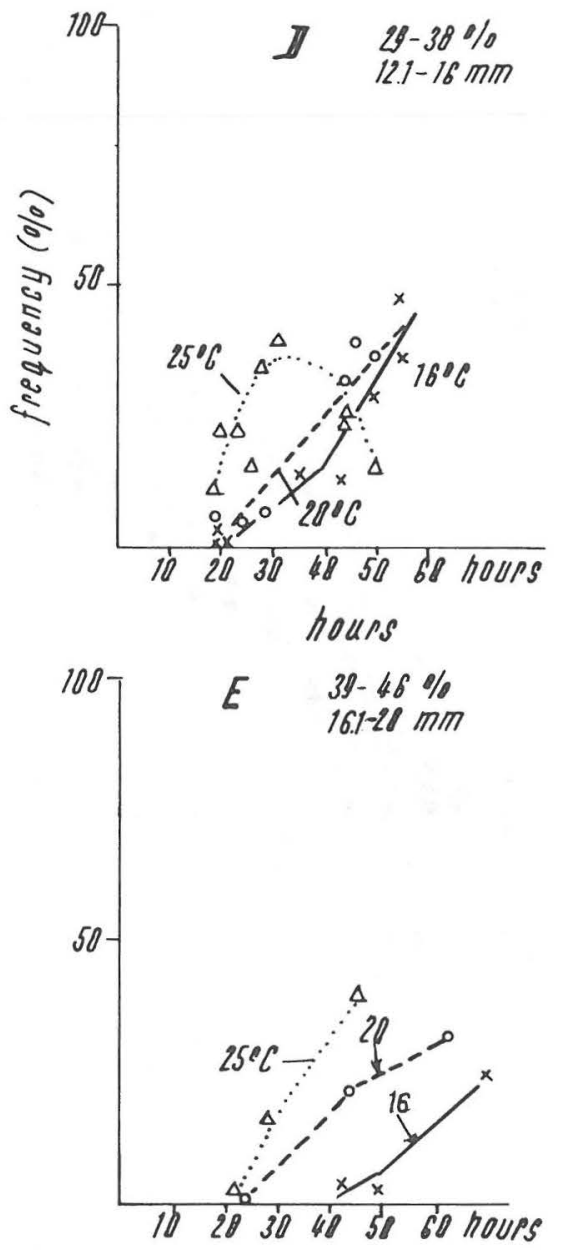

shedding of spores occurs in 24-h periods, mostly in the afternoon or evening. The shedding is strongly affected by circumstantial factors. Of these they considered the fluctuation in humidity to be the most significant.

An experiment was carried out in order to establish the effect of humidity upon the shedding of the spores and the leaps in the opening of the cap.

The opening of the cap was again filmed while the humidity of the air was altered. Fig. 5 shows the opening of the caps of some of the mushrooms seen in the film. Conditions were similar to those described for Fig. 4, except for the rapid changing of humidity. 
Fig. 4. Opening of the mushroom cap. The process was filmed by the Instrument and Measuring Technical Service of the Hungarian Academy of Sciences, Hungary. For evaluation a Film Motion Analyser (Camera Service Company, Nissei Sangyo Co. Ltd., Japan) was used. Numbers beside the marks are serial numbers of the mushrooms.

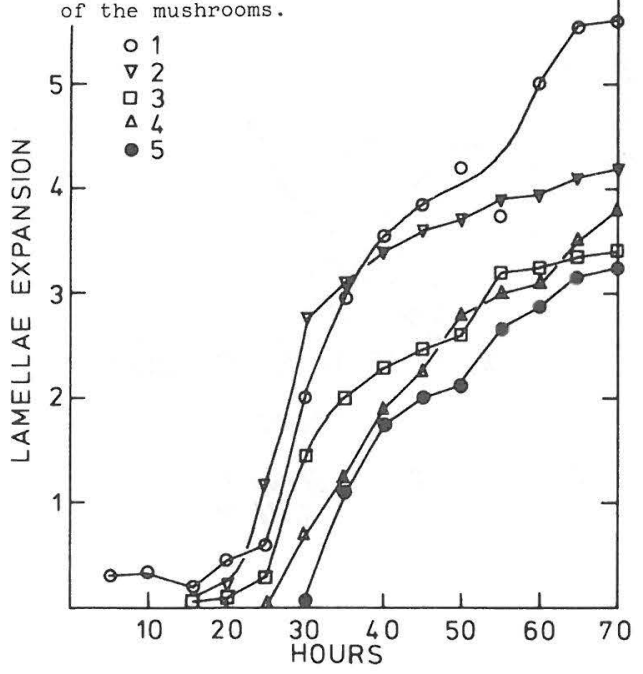

Fig. 5. Opening of the cap. Conditions were similar to those described for Fig. 4, except

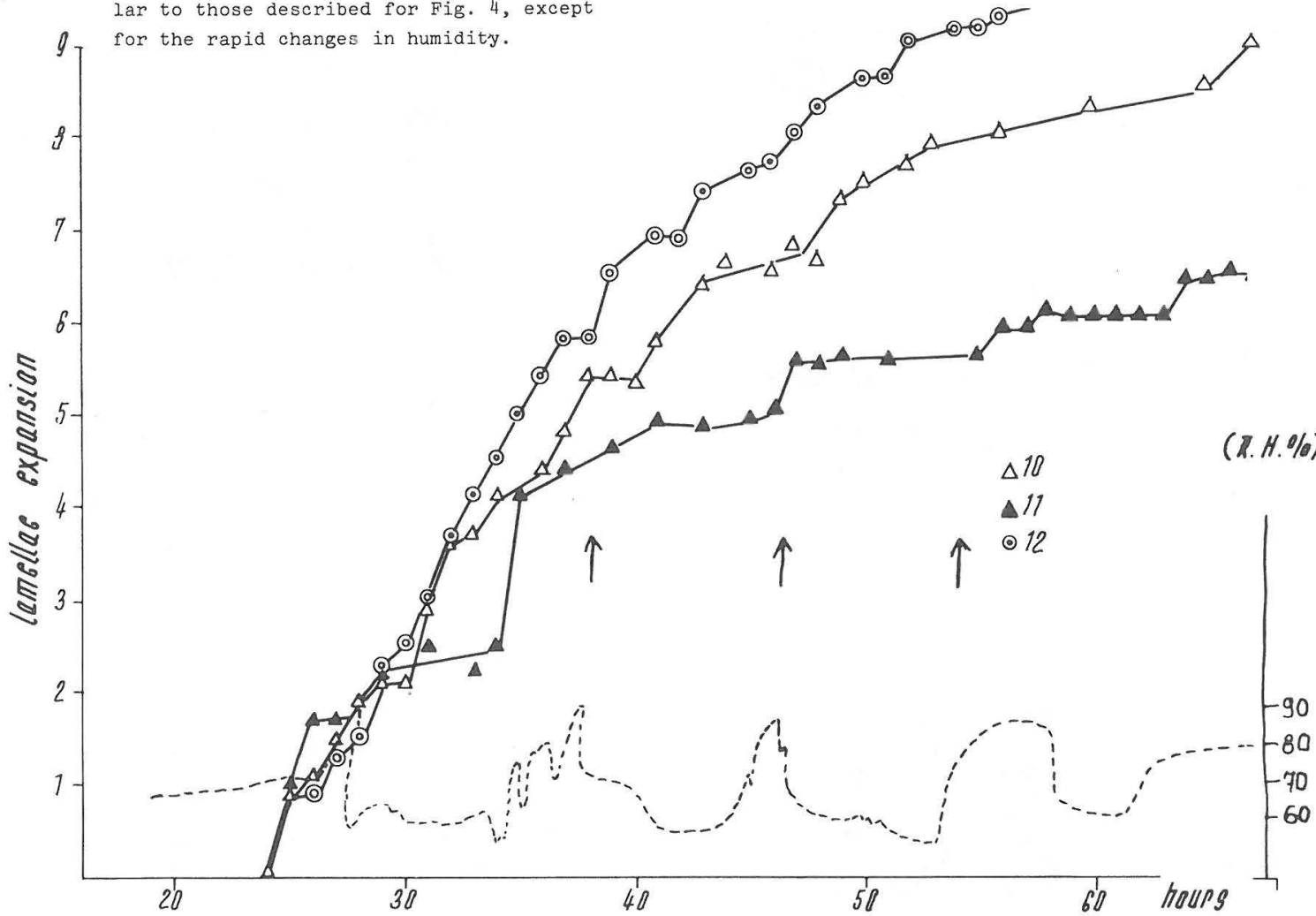

It may be seen in Fig. 5 that a sudden increase of humidity results in a leap in the opening of caps. This corresponds to the observations of the above mentioned authors, who found that mushrooms responded to a sudden increase of humidity by shedding their spores. The shedding of spores may be a mechanical consequence of the sudden opening of the caps.

The results of the experiments may be useful to the expert responsible for the storage of mushrooms. The following conclusions are to be taken into account: The humidity of the air must not fluctuate during storage. The degree of opening is related to the ripening and shedding of spores.

Mushrooms reach the state of complete maturity when they shed their spores, therefore the morphological eondition of the cap is characteristic of the degree of maturity of the individuum. Grading on the basis of the state of cap may result in better storage results but it is necessary to ensure a constant level of humidity and a temperature below $10^{\circ} \mathrm{C}$.

\section{References}

Hard, R.T. \& Kramer, C.L. 1970: Periodicity of spore 62: $1145-1169$.

Rockett, T.R. \& Kramer, C.L. 1974: Periodicity and total spore production by lignicolous Basidiomycetes. - Mycologia 66: 817-829. discharge in the Hymenomycetes. - Mycologia 